\title{
CD14 Expressing Cell Measurement
}

National Cancer Institute

\section{Source}

National Cancer Institute. CD14 Expressing Cell Measurement. NCI Thesaurus. Code C103365.

A count of the CD14 expressing cells per unit of a biological specimen. 